\title{
Behavior of the least shrew in a residential maze
}

\author{
JAMES L. WOLFE \\ Mississippi State University, Mississippi State, Mississippi 39762
}

\begin{abstract}
Five least shrews (Cryptotis parva) were tested individually for 4 days in a residential maze consisting of four arms radiating from a central nest chamber. Visits to arms and time spent in each were monitored electronically. Two arms were empty, one contained food, and one contained water. About $60 \%$ of daily activity occurred during darkness. There was much individual variation in circadian patterns. The average number of activity bouts was 12 during darkness and 9 during daylight. Short cycle length (bout plus interval) was 72 min during daylight and 54 min during darkness. Three individuals remained in the nest without feeding for periods greater than $5 \mathrm{~h}$ at a time for a total of 16 occasions during daylight hours. Exploratory behavior similar to that of mice was observed, with many visits to all arms occurring soon after introduction into the maze and declining rapidly thereafter. On Days 1 and 2 after introduction, the water arm was visited most frequently, followed by the food arm and empty arms. On Days 3 and 4, visits to the food arm were most frequent, followed by the water and empty arms.
\end{abstract}

Considerable attention has been paid to the activity patterns of shrews, especially as related to feeding activity and metabolic requirements (Buchalaczyk, 1972; Crowcroft, 1957; Gebczynski, 1965; Richardson, 1973; and many others). Here we investigate the behavior of the least shrew (Cryptotis parva) in a residential maze originally built for mice. This apparatus provides data for the assessment of the effect on activity of incentives in different arms, a description of exploratory behavior (new-place response), and a description of circadian and shorter activity rhythms.

The least shrew is active throughout the 24-h period but tends toward nocturnality (Whitaker, 1974). Nothing has been reported on patterns of exploration or short-term activity bouts.

\section{METHOD}

\section{Subjects}

Cryptotis parva is a small shrew, ranging from 4 to $5 \mathrm{~g}$ in weight. An excellent general account of this species is provided by Whitaker (1974). We tested five individuals collected by live trapping in east-central Mississippi. They are kept in groups of two and three in laboratory cages and fed crickets and mealworm larvae. During the 9 -month period of captivity, they have remained healthy, and two litters have been born to one female. Except for this female, their sexes have not been determined.

\section{Apparatus}

The mazes were constructed of stainless steel and consist of four arms radiating from a central chamber filled to within $15 \mathrm{~cm}$ of the top with sand. Dimensions are given in Figure 1.

Visits to the arms and duration of visits were monitored by photoelectric sensors and recorded on electric counters. The signal from the sensors also went to a 20-channel event recorder that recorded the time of occurrence and length of each visit. More details on the apparatus are provided in Wolfe and Esher (1978).

I thank R. J. Esher and Martha Robertson for assistance. Reprints available from J. L. Wolfe, Department of Biological Sciences, Mississippi State, Mississippi 39762.

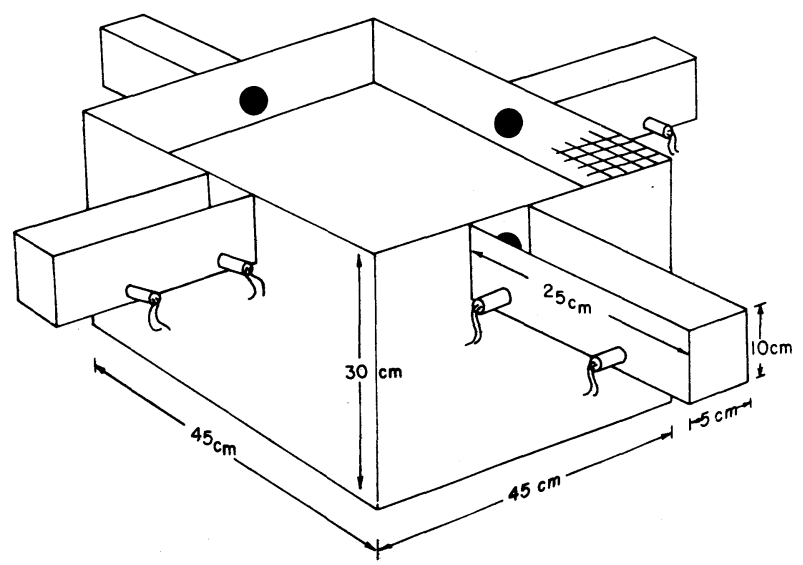

Figure 1. Diagram of the residential maze used in the study.

\section{Procedure}

The test room, housing five mazes, was kept near $23^{\circ} \mathrm{C}$ $\left(19^{\circ} \mathrm{C}-25^{\circ} \mathrm{C}\right)$ and on a $12 \mathrm{~h}$ photoperiod. Illumination during the day was provided by a bank of fluorescent lights in the ceiling. These lights were timed to go on at 0600 and off at 1800 . At night the mazes were dimly illuminated by beams of red light crossing the arms. Thus, the arms were illuminated slightly more during the dark period than was the central chamber.

Live crickets were restrained in the end of the food arm by passing a fine insect pin through the edge of the thoracic exoskeleton and pinning the insects to a block of soft wood. They were checked twice daily and kept constantly available. Water was provided in the end of another arm from a drinking bottle with a sipper tube.

When testing began, individual shrews were placed, with the nest from their home cages, in a shallow depression in the center of the middle compartment. They returned to and slept in the nest when inactive. Each animal was tested for 4 days. During the test of one individual, there was an electrical malfunction for part of 2 days, and these data were excluded.

\section{RESULTS AND DISCUSSION}

The circadian pattern tended to be nocturnal, with just over $60 \%$ of the day's activity occurring during 


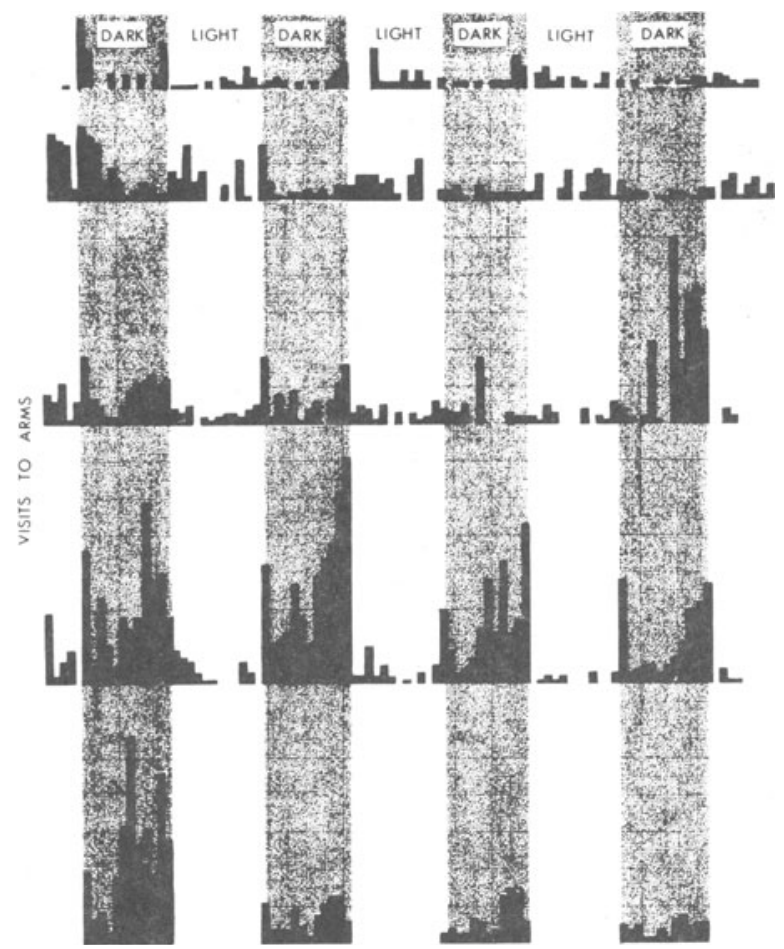

Figure 2. Circadian activity patterns of five Cryptotis parva, over a 4-day period. Activity is expressed as total visits to all arms of the maze.

Table 1

Means and Standard Errors of Characteristics of Activity Bouts on Days 1 and 4 of Testing

\begin{tabular}{|c|c|c|c|c|c|c|c|c|}
\hline & \multicolumn{4}{|c|}{ Day 1} & \multicolumn{4}{|c|}{ Day 4} \\
\hline & \multicolumn{2}{|c|}{ Light } & \multicolumn{2}{|c|}{ Dark } & \multicolumn{2}{|c|}{ Light } & \multicolumn{2}{|c|}{ Dark } \\
\hline & Mean & SD & Mean & SD & Mean & SD & Mean & SD \\
\hline Number & 9.0 & 2.5 & 12.7 & 2.6 & 8.3 & 1.8 & 10.7 & 1.5 \\
\hline Duration & 19.1 & 3.2 & 16.0 & 2.4 & 15.2 & 3.1 & 16.3 & 2.8 \\
\hline Interval & 50.0 & 6.0 & 34.2 & 2.9 & 59.2 & 8.3 & 41.6 & 3.7 \\
\hline
\end{tabular}

Note $-N=5$ animals.

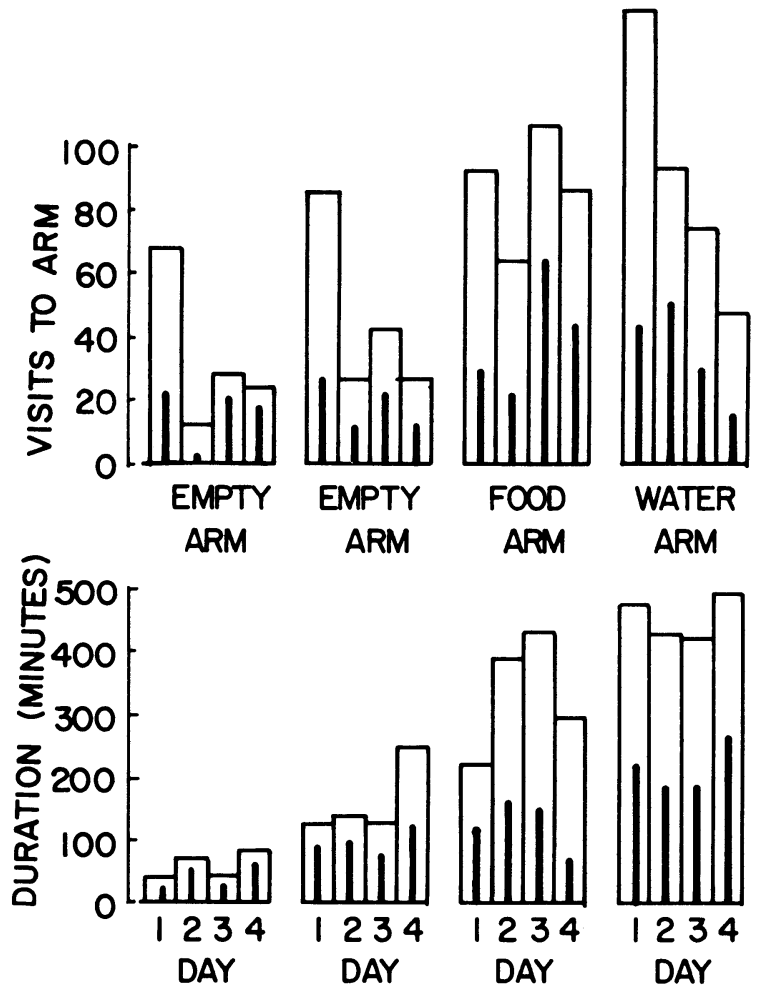

Figure 3. Pattern of visits to and time spent in the four maze arms over a 4-day period. Open bars are means $(\mathrm{N}=5)$, solid lines inside means are standard errors.

darkness. As Figure 2 indicates, there was considerable individual variation. The bottom individual in the figure was strictly nocturnal and apparently did not feed (no evidence of stored food in nest) for 12-h periods. Individuals illustrated toward the top of the figure were practically arrhythmic.

The pattern of visits to arms and time spent in them during the 4-day test is illustrated in Figure 3 (see also Table 1). The higher number of visits on Day 1 were much shorter than on subsequent days. Total time spent in the arms on Day 1 was slightly less than or about
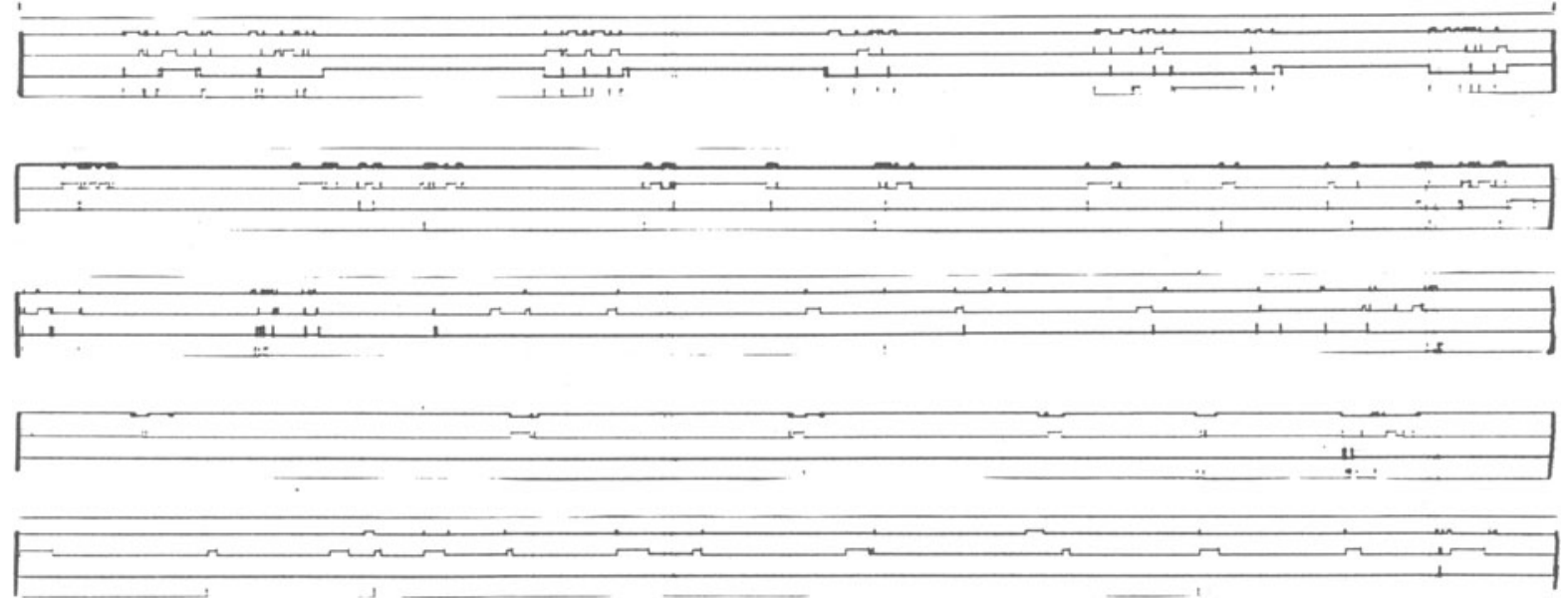

Figure 4. Strip-chart record of activity of five shrews over a 6 -h period $(6: 00 \mathrm{p} . \mathrm{m}$. to midnight), illustrating the periodicity of activity. 
Table 2

Relation of Size (in Grams) to Activity (in Minutes) in Three Shrews

\begin{tabular}{cccc}
\hline & & \multicolumn{2}{c}{ Activity } \\
\cline { 3 - 4 } Species & Size & "Short & Total \\
Suncusthm" & 36 & 133 & $(24 \mathrm{~h})$ \\
Blarina & 18 & 103 & 315 \\
Cryptotis & 5 & 65 & 264 \\
\hline
\end{tabular}

equal to that of Days $2-4$. The overall pattern was reasonably similar to the plus-maze behavior of rats and mice (Barnett \& Smart, 1975; Cowan, 1975). One exception was the strong response to water exhibited by Cryptotis.

The "short rhythm" of activity of Cryptotis is illustrated in Figure 4. Activity bouts were more frequent during darkness (Table 1). The number and length of bouts decreased after Day 1 . The duration of activity bouts was fairly constant at about $16 \mathrm{~min}$. The interval between bouts in light was about $60 \mathrm{~min}$. These together make a "short cycle" during daylight hours of $76 \mathrm{~min}$. The corresponding short cycle for the dark period was $57 \mathrm{~min}$. Thus, the species shows a pattern of shorter, more frequent periods of activity during darkness.

Richardson (1973) found Blarina brevicauda (shorttailed shrew) to be about three times as active during darkness as during light, whereas the larger Suncus murinus (musk shrew) was about twice as active during darkness. Blarina demonstrated less total activity and shorter feeding bouts than Suncus. Less overall activity and more intensive feeding are interpreted as energyconserving features of the smaller shrew. Table 2 provides a comparison of Cryptotis with these two species. Our data do not support the hypothesis of less total activity with decreasing size (and increasing metabolism). The trend of more frequent activity bouts with decreasing size is, however, supported.

\section{REFERENCES}

Barnetr, S. A., \& Cowan, P. E. Activity, exploration, curiosity, and fear: An ethological study. Interdisciplinary Science Reviews, 1976, 1, 43-62.

Barnet, S. A., \& Smart, J. L. The movements of wild and domestic house mice in an artificial environment. Behavioral Biology, 1975, 15, 85-93.

BuChalaczy K, A. Seasonal variations in the activity of shrews. Acta Theriologica, 1972, 17, 221-243.

Cowan, P. E. Activity, new place and new object reactions of several Rattus species. Doctoral dissertation, The Australian National University, 1975.

Crowcroft, P. The life of the shrew. London: Reinhold, 1957.

Gebczynski, M. Seasonal and age changes in the metabolism and activity of Sorex araneus. Acta Theriologica, 1965, 10, 303-331.

Richardson, J. H. Locomotory and feeding of the shrews, Blarina brevicauda and Suncus murinus. American Midland Naturalist, 1973, 90, 224-227.

Whitaker, J. D. Cryptotis parva. Mammalian species, No. 43. American Society of Mammalogists, 1974, 43, 1-8.

Wolfe, J. L., \& Esher, R. J. The behavior of a burrowing mouse, Peromyscus polionotus, in a residential maze. Journal of the Mississippi Academy of Sciences, 1978, 23, 100-109.

(Received for publication December 11, 1979) 